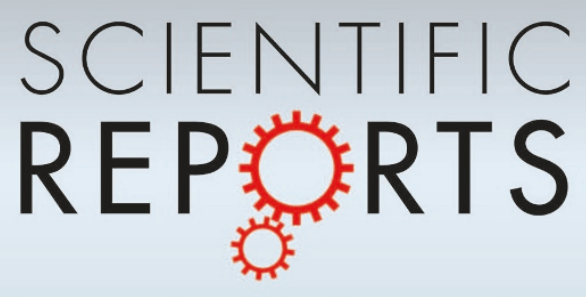

OPEN

SUBJECT AREAS:

ELECTRONIC PROPERTIES

AND MATERIALS

STRUCTURAL PROPERTIES

SYNTHESIS AND PROCESSING

CARBON NANOTUBES AND FULLERENES

Received

17 April 2013

Accepted

19 July 2013

Published

9 August 2013

Correspondence and requests for materials should be addressed to

C.H. lann.huang@ materials.ox.ac.uk)

\section{One-step spray processing of high power all-solid-state supercapacitors}

\author{
Chun Huang \& Patrick S. Grant
}

Department of Materials, University of Oxford, Parks Road, Oxford, OXI 3PH, UK.

Aqueous suspensions of multi-wall carbon nanotubes (MWNTs) in dilute $\mathrm{H}_{2} \mathrm{SO}_{4}$ were sprayed onto both sides of a Nafion membrane and dried to fabricate flexible solid-state supercapacitors. A single cell with MWNT-only electrodes had a capacitance of $57 \mathrm{~F} \mathrm{~g}^{-1}$ per electrode at $2 \mathrm{mV} \mathrm{s}^{-1}$ and $44 \mathrm{~F} \mathrm{~g}^{-1}$ at $150 \mathrm{mV} \mathrm{s}$ but with low $\mathrm{H}^{+}$mobility. Cells with MWNT + ionomer hybrid electrodes showed higher $\mathrm{H}^{+}$mobility, and the electric double layer (EDL) capacitance increased to $145 \mathrm{~F} \mathrm{~g}^{-1}$ at $2 \mathrm{mV} \mathrm{s}{ }^{-1}$ and $91 \mathrm{~F} \mathrm{~g}^{-1}$ at $150 \mathrm{mV} \mathrm{s}$. The energy and power densities of one electrode charged to $1 \mathrm{~V}$ at $1 \mathrm{~A} \mathrm{~g}^{-1}$ were $12.9 \mathrm{Wh} \mathrm{kg}^{-1}$ and $3.3 \mathrm{~kW}$ $\mathrm{kg}^{-1}$ respectively. Three solid-state supercapacitor cells connected in series charged to $3 \mathrm{~V}$ at 1 and $2 \mathrm{~A} \mathrm{~g}^{-1}$ provided a device power density of $8.9 \mathrm{~kW} \mathrm{~kg}^{-1}$ at $1 \mathrm{~A} \mathrm{~g}^{-1}$ and $9.4 \mathrm{~kW} \mathrm{~kg}{ }^{-1}$ at $2 \mathrm{~A} \mathrm{~g}^{-1}$, the highest for all-solid-state EDL supercapacitors.

ortable electronic devices such as mobile phones, tablets, notebook computers and some medical devices are increasingly seeking thin, lightweight and flexible energy storage technologies to enable future designs ${ }^{1,2}$. The primary energy storage technologies for existing designs are batteries such as Li-ion, although there are niche applications emerging for higher power density but lower energy density supercapacitors ${ }^{3-5}$. However, the production of thin, lightweight and flexible energy storage devices of any type using processes scalable to commercial implementation remains challenging ${ }^{6}$. For example, the design flexibility for Li ion battery and supercapacitor devices is somewhat constrained by current electrode manufacturing techniques based on slurry casting of 40-200 $\mu \mathrm{m}$ thick electrodes, and the need to robustly package and contain the potentially inflammable and toxic liquid electrolytes that are in widespread use.

The configuration of a conventional supercapacitor is an ion-permeable, electrically insulating separator sandwiched between two very high surface area electrodes (usually based on activated carbon) flooded with a liquid electrolyte and sealed in a package that is required to retain the electrolyte (preventing leakage and possible combustion) and to provide mechanical integrity. Although liquid electrolytes generally provide high ion (usually $\mathrm{Li}^{+}$) mobility, there are continuing efforts to replace these electrolytes with more benign aqueous-based and even solid-state electrolytes in order to realise potential savings in unit, production and lifetime costs. These approaches essentially trade a lower operating voltage, typically reduced from $\sim 3 \mathrm{~V}$ for $\mathrm{Li}^{+}$containing organic electrolytes to $\sim 1 \mathrm{~V}$ for aqueous electrolytes ${ }^{3}$, for improved environmental compatibility; for a solid-state electrolyte, reduced ion mobility is traded for greater design flexibility, especially for flexible or conformal battery or supercapatior designs, and greater safety ${ }^{7}$.

Most of the solid-state supercapacitor configurations studied have shown encouraging mechanical flexibility and comprised a gel-form electrolyte of polyvinyl alcohol (PVA) mixed with a strong acid such as $\mathrm{H}_{2} \mathrm{SO}_{4}$ or $\mathrm{H}_{3} \mathrm{PO}_{4}$. The acid-PVA gels act as both electrolyte and electrical separator, with the two electrodes on either side of the acid-PVA gel. Meng et al. ${ }^{8}$ reported a capacitance of $332 \mathrm{~F} \mathrm{~g}^{-1}$ for polyaniline (PANI)/carbon nanotube (CNT) electrode materials with a $\mathrm{H}_{2} \mathrm{SO}_{4}$-PVA gel electrolyte, but with a low power density of $2.1 \mathrm{~kW} \mathrm{~kg}^{-1}$. $\mathrm{Hu}$ et al..$^{9}$ reported $116 \mathrm{~F} \mathrm{~g}^{-1}$ at $2 \mathrm{mV} \mathrm{s}^{-1}$ for carboxylic functionalised single-wall carbon nanotubes (SWNTs) on cotton paper with a $\mathrm{H}_{3} \mathrm{PO}_{4}$-PVA gel electrolyte. Liu et al. ${ }^{10}$ reported $477 \mathrm{~F} \mathrm{~g}^{-1}$ at $0.4 \mu \mathrm{A} \mathrm{mm}{ }^{-2}$ for PANI/ $\mathrm{SWNT} / \mathrm{TiO}_{2}$ nanocomposite on highly oriented pyrolytic graphite (HOPG) electrodes with a $\mathrm{H}_{3} \mathrm{PO}_{4}-\mathrm{PVA}$ electrolyte.

However, hot pressing of the electrodes onto the electrolyte gel to promote infiltration and to form a simple thin supercapacitor cell is hard to regulate and it is difficult to avoid electrical shorts across the gel. Further, the stability of the gel electrolyte can be sensitive to environmental conditions, and flexibility and performance tend to deteriorate over time as the electrolyte dries. More mechanically robust solid-state electrolytes have been investigated, for example, a $\mathrm{Li}_{2} \mathrm{~S}-\mathrm{P}_{2} \mathrm{~S}_{5}$ glass-ceramic electrolyte with MWNT electrodes but which had a low capacitance of $7.7 \mathrm{~F} \mathrm{~g}^{-111}$; a polyvinylidene fluoride (PVDF)/lithium trifluoromethanesulfonate (LiTFS) separator with 
poly(thylene oxide) (PEO)/lithium perchlorate $\left(\mathrm{LiClO}_{4}\right)$ polymer electrolyte infiltrated with $\mathrm{K}_{3} \mathrm{Fe}(\mathrm{CN})_{6} / \mathrm{K}_{4} \mathrm{Fe}(\mathrm{CN})_{6}$ mediators achieved $139 \mathrm{~F} \mathrm{~g} \mathrm{~g}^{-1}$ at $10 \mathrm{mV} \mathrm{s}^{-1}$ with porous carbon electrodes, but again with a low power density of $1.3 \mathrm{~kW} \mathrm{~kg}^{-112}$; and a $\mathrm{H}_{4} \mathrm{SiW}_{12} \mathrm{O}_{40}$ (SiWA)- $\mathrm{H}_{3} \mathrm{PO}_{4}$-PVA polymer electrolyte provided $1 \mathrm{mF} \mathrm{cm}{ }^{-2}$ at $1 \mathrm{~V} \mathrm{~s}^{-1}$ with graphite electrodes ${ }^{13}$ and $50 \mathrm{mF} \mathrm{cm}{ }^{-2}$ at $500 \mathrm{mV} \mathrm{s}^{-1}$ with $\mathrm{RuO}_{2} / \mathrm{TiO}_{2}$ electrodes ${ }^{14}$.

In this paper, an all-solid-state supercapacitor was fabricated by spraying aqueous suspensions of multi-wall carbon nanotubes (MWNTs) in $0.5 \mathrm{M} \mathrm{H}_{2} \mathrm{SO}_{4}$ directly onto both sides of a Nafion proton conducting membrane, which was heated at $100^{\circ} \mathrm{C}$ throughout deposition to evaporate water as the mesoporous MWNT-based electrodes formed. Fig. 1(a) is a schematic diagram of the spray deposition arrangement; Fig. 1(b) shows a membrane covered with the sprayed MWNT-based electrode on both sides; and Fig. 1(c) is a schematic diagram of the fabricated solid-state supercapacitor full cell including $\mathrm{Cu}$ foil current collectors which were added onto either electrode by gentle manual pressing. Unlike the other fabrication methods of solid-state supercapacitors, the processing described in this paper is fast and straightforward, with no hot pressing. Even though the resulting simple two electrode cell was essentially "dry" and required no re-immersion in an electrolyte source, sufficient $\mathrm{H}^{+}$ species were retained because spraying and forming the MWNTbased electrodes incrementally in the presence of $0.5 \mathrm{M} \mathrm{H}_{2} \mathrm{SO}_{4}$ ensured the $\mathrm{H}^{+}$ions fed into all parts of the interior of the electrode, promoting electrolyte wetting and ion adsorption. Then to increase $\mathrm{H}^{+}$mobility, Nafion short chain ionomer was added into the aqueous suspensions during spraying to create a hybrid porous electrode, comprising MWNTs coated with ionomer. Fig. 1(d) is a schematic diagram showing that three $4.5 \mathrm{~cm} \times 4 \mathrm{~cm} \times 230 \mu \mathrm{m}$ cells were (a)

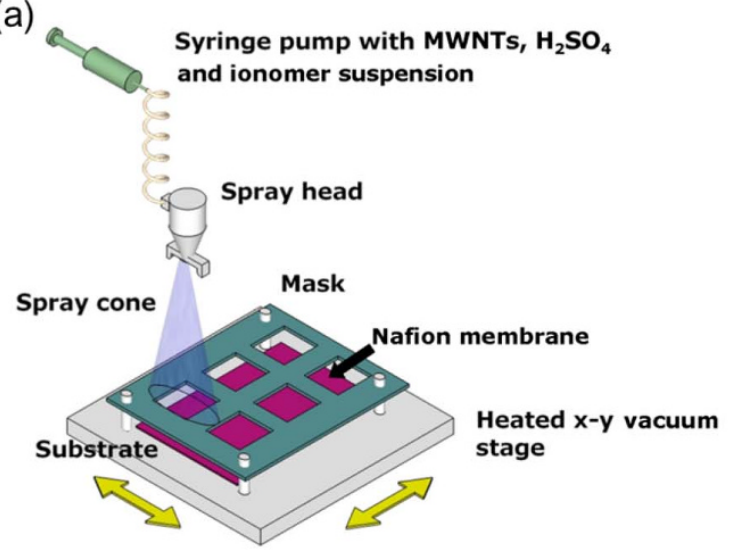

(b)

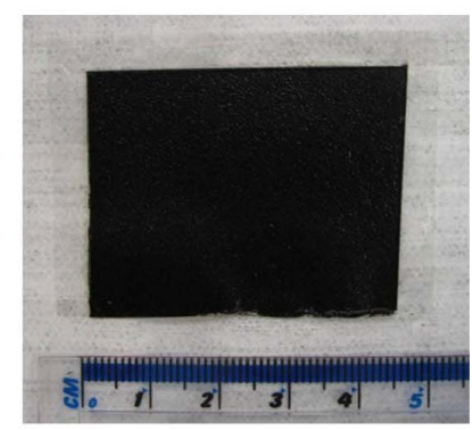

(c)

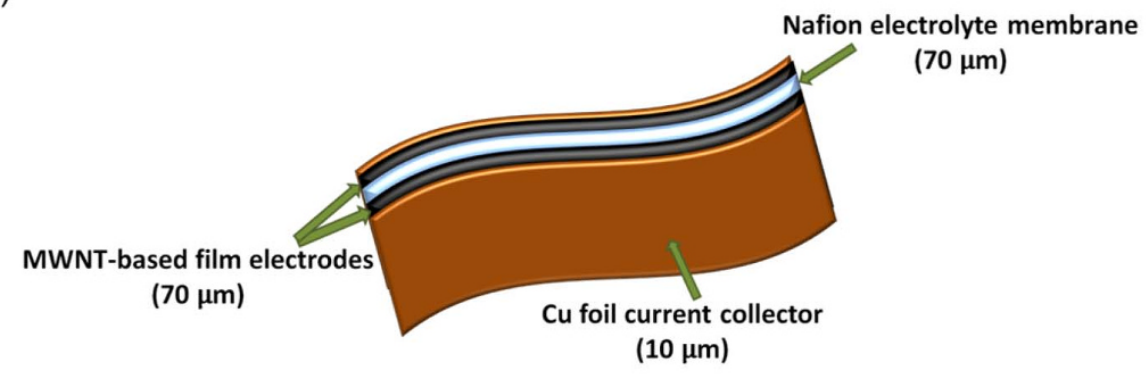

(d)

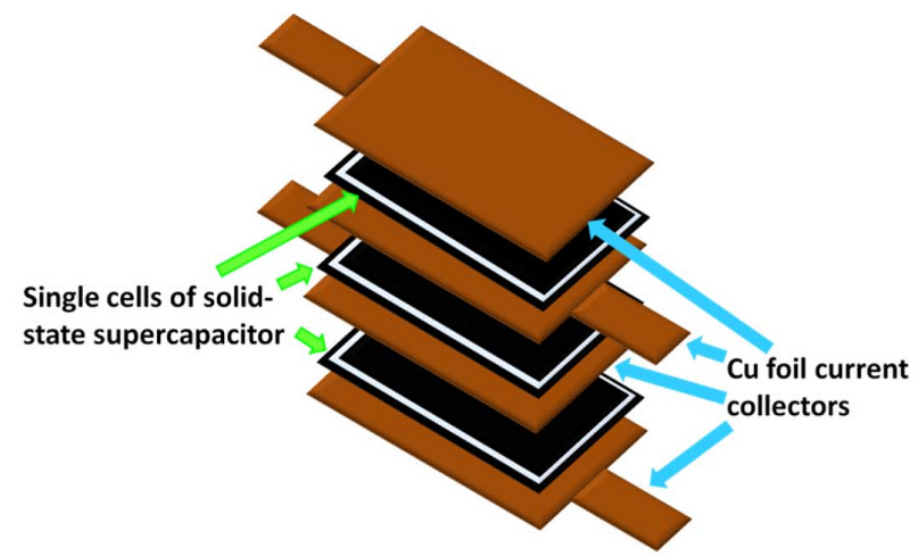

Figure 1 (a) A schematic diagram of the spray deposition arrangement used to fabricate solid-state supercapacitors; (b) a solid-state supercapacitor cell comprising a Nafion membrane covered with spray deposited MWNT-based electrodes; (c) a schematic diagram of a membrane-based allsolid-state supercapacitor; and (d) a schematic diagram of a simple "stack" of three all-solid-state supercapacitor cells. 
stacked and connected in series to operate at $3 \mathrm{~V}$ and 1 and $2 \mathrm{~A} \mathrm{~g}^{-1}$ and produced a power density of $8.9 \mathrm{~kW} \mathrm{~kg}^{-1}$ at $1 \mathrm{~A} \mathrm{~g}^{-1}$ and $9.4 \mathrm{~kW}$ $\mathrm{kg}^{-1}$ at $2 \mathrm{~A} \mathrm{~g}^{-1}$.

\section{Results}

Membrane-based solid-state supercapacitors with MWNT-only electrodes. In order to establish baseline behaviour against which the subsequent effect of ionomer additions could be assessed, a solidstate supercapacitor with MWNT-only electrodes was firstly studied. Fig. 2(a) shows the cyclic voltammograms (CVs) of a double-side sprayed full cell solid-state supercapacitor with the membrane sandwiched between the two MWNT + 0.1 wt $\%$ sodium dodecylbenzenesulfonate (SDBS) only electrodes normalised by the square root of scan rate, which can be used to better enable the resolution of low scan rate behaviour when a wide range of scan rates is studied. The CVs in Fig. 2(a) were highly resistive in character with restricted ion mobility during charging and discharging, and were illustrative of typical problems for solid-state supercapacitors ${ }^{18}$. The CV current increased asymmetrically about zero current at very slow scan rates of 1 and $2 \mathrm{mV} \mathrm{s}^{-1}$, probably due to electron percolation through the Nafion membrane due to a small fraction of MWNTs that were drawn into the membrane. The CV shape indicates little electric double layer (EDL) or pseudo-capacitive behaviour giving a specific capacitance of $57 \mathrm{~F} \mathrm{~g}^{-1}$ per electrode at $2 \mathrm{mV} \mathrm{s}^{-1}$ and $44 \mathrm{~F}$ $\mathrm{g}^{-1}$ at $150 \mathrm{mV} \mathrm{s}^{-1}$, compared with $86 \mathrm{~F} \mathrm{~g}^{-1}$ at $150 \mathrm{mV} \mathrm{s}^{-1}$ for the same electrode showing EDL behaviour in aqueous $1 \mathrm{M} \mathrm{H}_{2} \mathrm{SO}_{4}$ (Supplementary Fig. S1(a)). In order to check for any reaction with
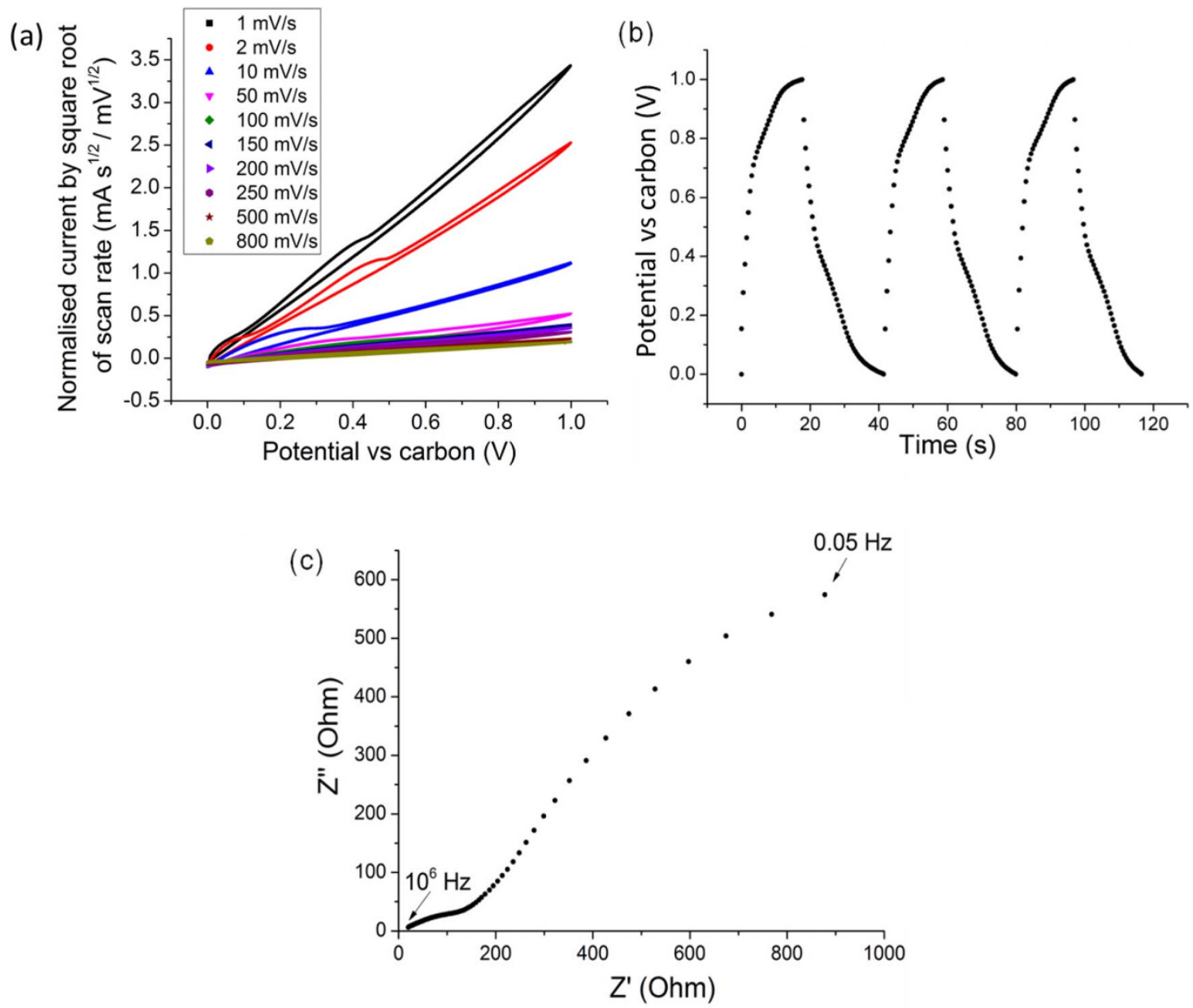

Figure 2 (a) Cyclic voltammograms of a full cell membrane-based solid-state supercapacitor with MWNT-only electrodes normalised by the square root of the scan rate; (b) DC galvanostatic charge/discharge curves of the same solid-state supercapacitor at $1 \mathrm{~A} \mathrm{~g}^{-1}$; and (c) the complementary Nyquist impedance plot between $10^{6} \mathrm{~Hz}$ and $0.05 \mathrm{~Hz}$. the $\mathrm{Cu}$ current collector, both carbon coated and uncoated $\mathrm{Cu}$ current collectors were studied under identical conditions and no difference or resolvable reactions were measured. Graphite current collectors can also be used ${ }^{15}$. The solid-state energy density was 6.1 Wh kg-1, comparable with $7 \mathrm{Wh} \mathrm{kg}^{-1}$ for SWNTs in a $7.5 \mathrm{M}$ $\mathrm{KOH}$ electrolyte ${ }^{19}$ and $3.9 \mathrm{Wh} \mathrm{kg}^{-1}$ for MWNTs in a $\mathrm{H}_{2} \mathrm{SO}_{4}$ electrolyte $^{20}$; the power density was $1.1 \mathrm{~kW} \mathrm{~kg}$, in the lower range of $0.01-10 \mathrm{~kW} \mathrm{~kg}^{-1}$ for commercial supercapacitor power densities with liquid electrolytes ${ }^{16,21,3}$.

Fig. 2(b) shows the corresponding DC galvanostatic charge/discharge curves at a potential range of $1 \mathrm{~V}$ at $1 \mathrm{~A} \mathrm{~g}^{-1}$ with a similar specific capacitance estimated from the charge/discharge curves of $47 \mathrm{~F} \mathrm{~g}^{-1}$. The IR drop associated with internal resistance of the capacitor at the beginning of each charge and discharge cycle was $\sim 0.14 \mathrm{~V}$, compared with $\sim 0.1 \mathrm{~V}$ for the equivalent aqueous electrolyte (Supplementary Fig. S1(b)).

Fig. 2(c) is the corresponding Nyquist plot showing that at high frequency, the intersection of the best-fit curve to the data with the real axis (indicative of the equivalent series resistance (ESR) of electrolyte and current collector $^{22}$ ) was estimated at $\sim 19 \Omega \mathrm{cm}^{2}$ and much higher than $1 \Omega \mathrm{cm}^{2}$ for the equivalent liquid-based electrolyte (Supplementary plementary Fig. S1(c)) and $0.48 \Omega \mathrm{cm}^{2}$ for MWNTs electrophoretically deposited onto Ni foils in a $6 \mathrm{M} \mathrm{KOH}$ electrolyte $^{23}$.

In summary, spray processing conveniently produced thin ( $\sim 70 \mu \mathrm{m}$ thick for each electrode) and compact solid-state supercapacitors but performance was undermined by a limited EDL (b) 
response because of a combination of high ESR and limited ionic mobility when compared with aqueous electrolyte equivalents.

Membrane-based solid-state supercapacitors with MWNT + ionomer hybrid electrodes. Fig. 3(a) shows a scanning electron micrograph of the as-sprayed MWNT + ionomer electrode, where the ionomer readily provided suspension stability without the need for additional surfactants ${ }^{17}$. Fig. $3(\mathrm{~b})$ is a transmission electron micrograph of the dried MWNTs co-sprayed with the ionomer showing how the ionomer coated the majority of the length of the MWNTs, with a thickness approximately comparable with the MWNT diameter of $\sim 10 \mathrm{~nm}$.

Fig. 4(a) shows the normalised CVs of a full cell solid-state supercapacitor with MWNT + ionomer hybrid electrodes. The CVs were more box-like than the MWNT $+0.1 \mathrm{wt} \%$ SDBS based electrodes in Fig. 2(a), with current now increasing much more readily on potential sweep reversal, at all sweep rates. The current response was now more symmetrical and the overall CV behaviour was of an EDL supercapacitor $^{24}$. The ionomer coating over most of the MWNTs reduced any electron percolation through the membrane to a negligible effect, even at very slow scan rates. However, there was now a pair of broad peaks superimposed on the CVs at slow scan rates. Fig. 4(b) shows a plot of the height of these peaks as a function of the square root of scan rate up to $50 \mathrm{mV} \mathrm{s}^{-1}$ - beyond this, the peak height became negligibly small compared with the EDL response. The data fitted closely to a linear relationship showing that the reaction was reversible at these comparatively slow scan rates and diffusion controlled ${ }^{26-28}$. It is suggested that this reaction arises from interaction of the mobile $\mathrm{H}^{+}$ions (retained in the ionomer) and the

(a)

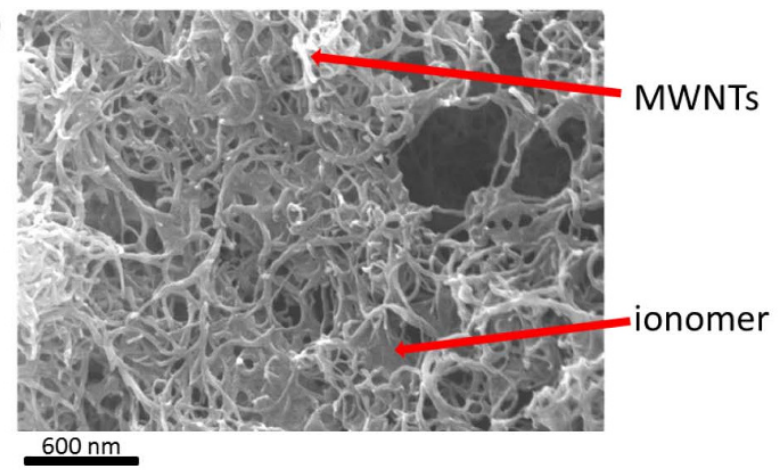

(b)

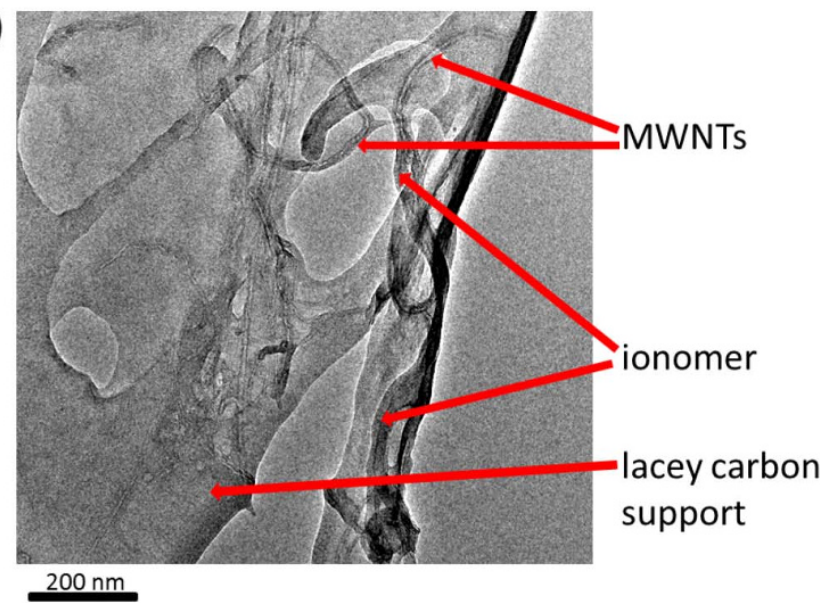

Figure 3 (a) Scanning electron micrograph of the spray deposited MWNT + ionomer hybrid electrode; and (b) transmission electron micrograph of the MWNTs with ionomer. negatively charged $\mathrm{F}^{-}$species present in the ionomer ${ }^{29}$. However, it should be emphasised that this redox-like activity was only significant at the slowest scan rates and the capacitance remained remarkably high at scan rates above $50 \mathrm{mV} \mathrm{s}^{-1}$, where pseudo-capacitive effects were less influential and charge storage was dominated by the EDL behaviour at the interface between the $\mathrm{H}^{+}$conducting ionomer and the electron conducting MWNTs.

The specific capacitance of a single cell with hybrid MWNT + ionomer electrodes estimated from the CV curves was $145 \mathrm{~F} \mathrm{~g}^{-1}$ per electrode at $2 \mathrm{mV} \mathrm{s}^{-1}$ and $91 \mathrm{~F} \mathrm{~g}^{-1}$ at $150 \mathrm{mV} \mathrm{s}^{-1}$, more than double the MWNT-only solid-state supercapacitor and now matching a MWNT electrode in a similar aqueous electrolyte.

Fig. 4(c) shows the corresponding DC galvanostatic charg/discharge curves at $1 \mathrm{~A} \mathrm{~g}^{-1}$ with an estimated capacitance of $92 \mathrm{~F} \mathrm{~g}^{-1}$ and an IR drop of $\sim 0.12 \mathrm{~V}$. As previously described for the CVs, the non-linearity in the charge/discharge curves after the IR drop was related to the redox activity in the electrodes at low current densities. Fig. 4(d) shows the corresponding Nyquist plot with an ESR now reduced from $19 \Omega \mathrm{cm}^{2}$ for the MWNT-only solid-state supercapacitor to $5.5 \Omega \mathrm{cm}^{2}$, and with a charge transfer resistance reduced from $\sim 180 \Omega \mathrm{cm}^{2}$ to $\sim 5 \Omega \mathrm{cm}^{2}$.

The capacitance of a supercapacitor can be described by ${ }^{25}$ :

$$
C(\omega)=C^{\prime}(\omega)-j C^{\prime \prime}(\omega)
$$

where $C^{\prime}$ and $C^{\prime \prime}$ are the real and imaginary part of the capacitance $C$, which depends on $\omega=2 \pi f$, where $f$ is the frequency. Both $C^{\prime}$ and $C^{\prime \prime}$ can be obtained from electrochemical impedance spectroscopy (EIS) by applying a small fluctuating voltage of $\pm 5 \mathrm{mV}$, where $C^{\prime \prime}$ relates to the energy dissipation in the system ${ }^{25,31}$.

From Equation 1:

$$
\begin{aligned}
& C^{\prime}(\omega)=\frac{-Z^{\prime \prime}(\omega)}{\omega|Z(\omega)|^{2}} \\
& C^{\prime \prime}(\omega)=\frac{Z^{\prime}(\omega)}{\omega|Z(\omega)|^{2}}
\end{aligned}
$$

where $Z^{\prime}$ and $Z^{\prime \prime}$ are the real and imaginary part of the impedance and were obtained by EIS measurements. In order to assess the effect of the ionomer addition on $\mathrm{H}^{+}$mobility, the relaxation time, also called the RC time constant $\tau_{0}$, with and without ionomer was estimated. $\tau_{0}$ can be obtained by plotting the variation of $C^{\prime \prime}$ as a function of frequency, and determining the frequency $f_{0}$ at which $C^{\prime \prime}$ was a maximum $^{25}$. The RC time constant is then obtained from $\tau_{0}=1 / f_{0} \cdot \tau_{0}$ also indicates the median charge storage efficiency ${ }^{32}$ that relates to the time needed to charge an EDL capacitor to $63.2 \%$ of its final capacitance. Consequently, $\tau_{0}$ is also related to the ionic mobility within the system ${ }^{25,33,34}$. The MWNT-only and MWNT + ionomer cells gave $\tau_{0}=1.3 \mathrm{~s}$ and $\tau_{0}=0.5 \mathrm{~s}$ respectively, while $\tau_{0}=0.03 \mathrm{~s}$ for the MWNT-only electrode in an aqueous $\mathrm{H}_{2} \mathrm{SO}_{4}$ electrolyte system. Portet et al. ${ }^{31}$ reported RC time constants of $0.7 \mathrm{~s}$ and $0.1 \mathrm{~s}$ for MWNT and carbon black electrodes respectively, in a liquid electrolyte of $1.5 \mathrm{M} \mathrm{NEt}_{4} \mathrm{BF}_{4}$ in acetonitrile.

The energy density of one MWNT + ionomer electrode in a solidstate supercapacitor was $12.9 \mathrm{Wh} \mathrm{kg}^{-1}$ and the power density was $3.3 \mathrm{~kW} \mathrm{~kg} \mathrm{~kg}^{-1}$. Futaba et al. ${ }^{35}$ reported a maximum energy density of $13 \mathrm{Wh} \mathrm{kg}^{-1}$ for vertically aligned single wall carbon nanotube (SWNT) film electrode in $1 \mathrm{M} \mathrm{Et}_{4} \mathrm{NBF}_{4} /$ propylene carbonate organic electrolyte over a $2.5 \mathrm{~V}$ voltage window. Liu et al. ${ }^{36}$ reported a maximum energy density of $0.5 \mathrm{Wh} \mathrm{kg}^{-1}$ and a maximum power density of $0.3 \mathrm{~kW} \mathrm{~kg}^{-1}$ for CNT-polyaniline nanocomposite electrode with a $\mathrm{PVA}-\mathrm{H}_{3} \mathrm{PO}_{4}$ gel electrolyte, and where the energy density was improved to $17 \mathrm{Wh} \mathrm{kg}^{-1}$ when $\mathrm{TiO}_{2}$ nanoparticles were incorporated to introduce pseudo-capacitance ${ }^{10}$. Meng et al. ${ }^{8}$ reported an energy density of $7.1 \mathrm{Wh} \mathrm{kg}^{-1}$ and a power density of $2.1 \mathrm{~kW} \mathrm{~kg}^{-1}$ for CNTpolyaniline nanocomposite electrode with a $\mathrm{PVA}-\mathrm{H}_{2} \mathrm{SO}_{4}$ gel electrolyte, within a $0.8 \mathrm{~V}$ voltage window. Therefore, at the time of writing, 

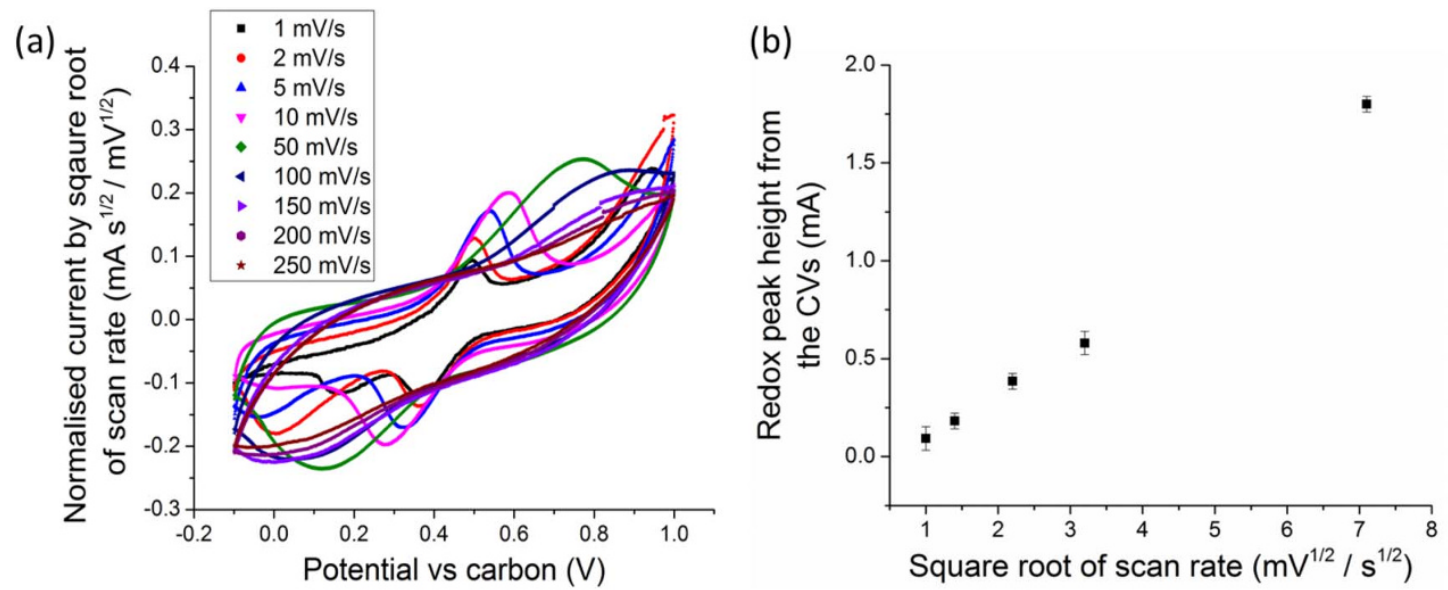

(c)

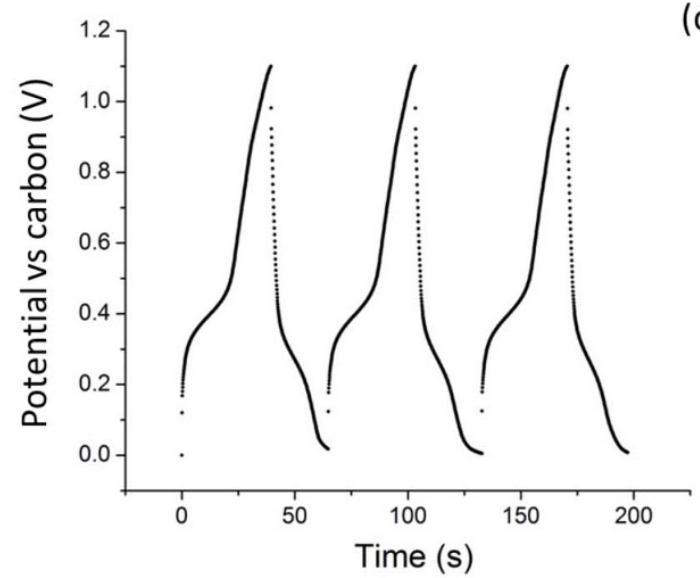

(d)

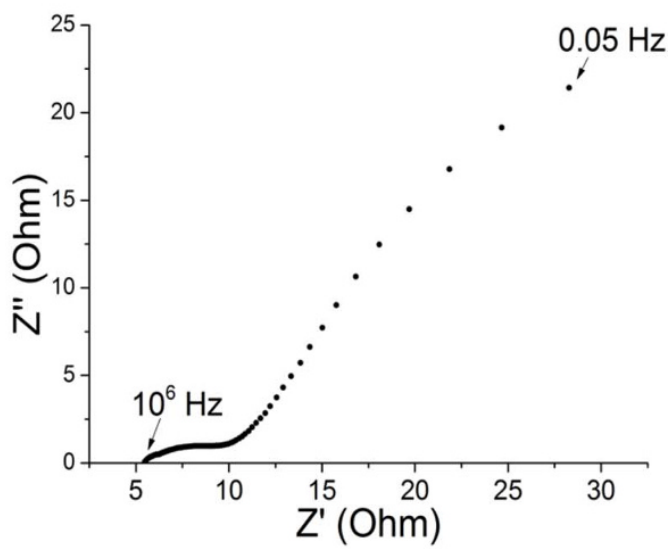

Figure 4 (a) Cyclic voltammograms of a full cell membrane-based solid-state supercapacitor with MWNT + ionomer electrodes normalised by the square root of the scan rate; (b) a plot of redox peak height from the CVs against square root of scan rate; (c) DC galvanostatic charge/discharge curves of the same solid-state supercapacitor at $1 \mathrm{~A} \mathrm{~g}^{-1}$; and (d) the complementary Nyquist impedance plot between $10^{6} \mathrm{~Hz}$ and $0.05 \mathrm{~Hz}$.

the energy and power densities achieved here are likely the highest for solid-state supercapacitors that make use of EDL capacitance only, and competitive with liquid electrolyte-based equivalents. Table 1 summarises the specific capacitances, energy and power densities of the MWNT-based electrode in both $1 \mathrm{M} \mathrm{H}_{2} \mathrm{SO}_{4}$ liquid electrolyte and in the full cell solid-state configuration, with all figures normalised to the performance of one electrode.

Aqueous electrolytes have limited voltage windows (typically $\sim 1 \mathrm{~V}$ ) if electrolysis of the water component is to be avoided ${ }^{30,37}$. Room temperature ionic liquids (RTILs) are complex liquid salts that are being intensively researched to provide a wider electrochemical stability (voltage) window without the need for air sensitive organic solvents ${ }^{38}$. However, solid-state supercapacitors also offer possibilities for a higher operating voltage window without resorting to organic liquids or RTILs since no solvents are required. As the energy and power densities depend on the operating voltage squared ${ }^{25}$, even small increases in voltage are advantageous, providing increases in resistance are avoided. Fig. 5(a) shows DC galvanostatic charge/discharge curves for a solid-state hybrid electrode supercapacitor charged to $2 \mathrm{~V}$, with little change in charging and discharging shape over time even at the higher voltage. Fig. 5(b) shows the energy and power densities of a solid-state hybrid electrode supercapacitor, charged across voltage windows in the range of 2 to $2.7 \mathrm{~V}$ at $1 \mathrm{~A}$ $\mathrm{g}^{-1}$. For voltage windows larger than $3 \mathrm{~V}$, additional broad peaks in the CVs suggested polymer breakdown and current collector oxidation. In this case, total mass of both the electrode and the current collector were taken in account to reflect more realistic gravimetric energy and power performance.

Solid-state supercapacitor devices made of cell stacks. Connecting solid-state supercapacitors in series by stacking the cells together through current collectors allows a higher working voltage and increases specific power and energy densities. In most previous studies, the dimensions of the fabricated solid-state supercapacitor stacks were relatively small (e.g. $5 \mathrm{~mm} \times 5 \mathrm{~mm} \mathrm{in}^{10}$ ), and scaling up towards the device scale posed difficulties in fabricating homogenous nanostructured electrodes over comparatively large areas, preventing short circuits over larger areas, etc. Here, the $4.5 \mathrm{~cm} \times 4 \mathrm{~cm}$ cells were readily stacked at a scale consistent with a medium format mobile device.

Table $1 \mid$ A summary of the performance of MWNT-based electrodes in $1 \mathrm{M} \mathrm{H}_{2} \mathrm{SO}_{4}$ and in a solid-state symmetrical membrane-based cell configuration. All values are calculated per electrode

\begin{tabular}{llccc} 
Electrode & Testing environment & Capacitance $\left(\mathrm{F} \mathrm{g}^{-1}\right)$ & Energy density $\left(\mathrm{Wh} \mathrm{kg}^{-1}\right)$ & Power density $\left(\mathrm{kW} \mathrm{kg}^{-1}\right)$ \\
\hline MWNT & $1 \mathrm{M} \mathrm{H}_{2} \mathrm{SO}_{4}$, half cell & 86 & 12 & 3.4 \\
MWNT & Solid-state configuration, full cell & 44 & 6.1 & 1.1 \\
MWNT + ionomer hybrid & Solid-state configuration, full cell & 91 & 12.9 & 3.3
\end{tabular}


(a)

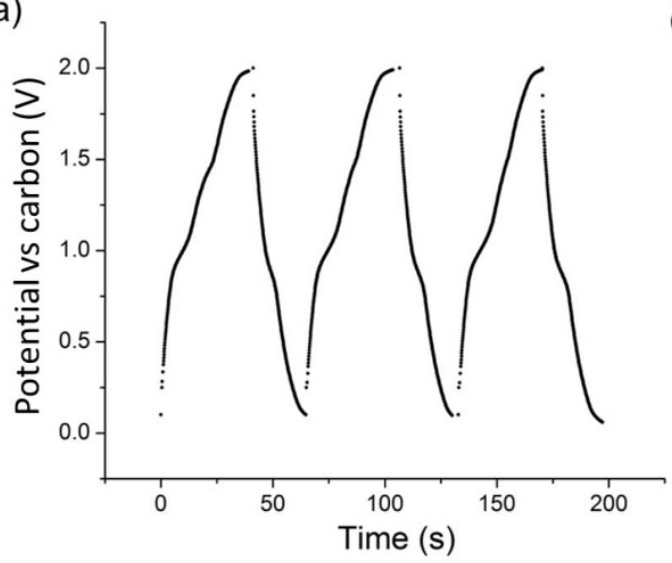

(b)

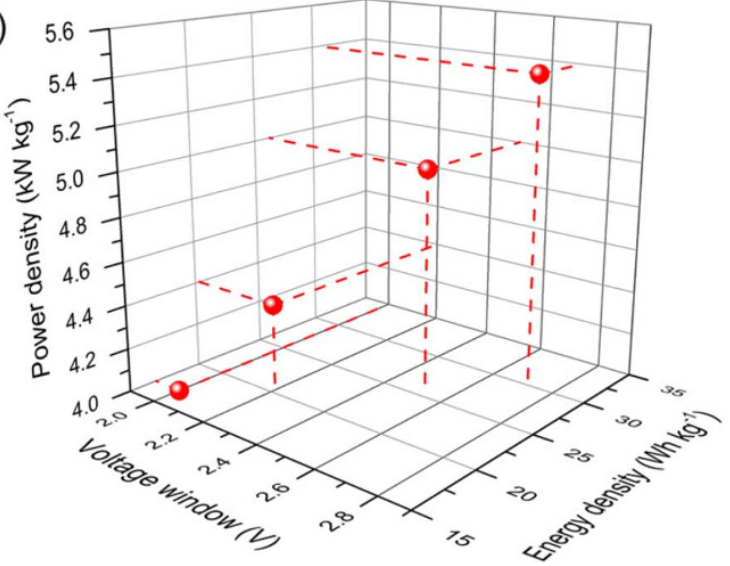

Figure 5 (a) DC galvanostatic charge/discharge curves charged to $2 \mathrm{~V}$ at $1 \mathrm{~A} \mathrm{~g}^{-1}$ for a full cell solid-state supercapacitor with MWNT + ionomer electrodes; and (b) specific energy and power densities against increasing voltage window from 2 to $2.7 \mathrm{~V}$.

Fig. 6(a) shows the CVs of two hybrid MWNT + ionomer solidstate supercapacitors connected in series. The CVs were parallelogram in shape even at a fast scan rate of $300 \mathrm{mV} \mathrm{s}^{-1}$. The applied voltage should ideally be shared equally by each cell in the stack where resistances and capacities are balanced ${ }^{37}$, so stacks have advantages over single cells where fast scan rates and charging/discharging kinetics are required.

Assuming each cell in the stack contributed the same capacitance, the capacitance of the stack can be estimated from ${ }^{37}$ :

$$
C_{\text {stack }}=\frac{C_{\text {single }}}{n}
$$

where $C_{\text {stack }}$ is the overall capacitance of the stack, $C_{\text {single }}$ is the capacitance of each individual cell and $n$ is the number of cells in the stack. Therefore, in a stack of 2 symmetrical cells, the overall capacitance of the stack is a half of that of a single cell ${ }^{39}$. The capacitance of the two cell stack calculated from Fig. $6(\mathrm{a})$ at $150 \mathrm{mV} \mathrm{s}^{-1}$ was $0.2 \mathrm{~F}$ with an energy density of $23 \mathrm{Wh} \mathrm{kg}^{-1}$ and power density of $4.2 \mathrm{~kW} \mathrm{~kg}^{-1}$. Comparison of the performance of this few-cell stack with the literature is difficult due to a lack of similar data, but the results are comparable with one of the highest reported capacitances of $0.21 \mathrm{~F}$ for a two-cell symmetrical supercapacitor stack, which used pseudocapacitive $\mathrm{MnO}_{x}$ /acid treated CNTs electrodes and a $2 \mathrm{M} \mathrm{KCl}$ aqueous solution electrolyte ${ }^{39}$.

Three cells were stacked in series and charged to $3 \mathrm{~V}$ at current densities of 1 and $2 \mathrm{~A} \mathrm{~g}^{-1}$ and Fig. 6(b) shows the galvanostatic charge and discharge curves for the three-cell stack. Because of the overall higher operating voltage, the IR drop increased to $0.75 \mathrm{~V}$ and marked resistance occurred after the voltage reached $2.7 \mathrm{~V}$ during charging, suggesting that loads may not be shared equally between the three cells. Nonetheless, the power density of the device was $8.9 \mathrm{~kW} \mathrm{~kg}^{-1}$ at $1 \mathrm{~A} \mathrm{~g}^{-1}$ and $9.4 \mathrm{~kW} \mathrm{~kg}^{-1}$ at $2 \mathrm{~A} \mathrm{~g}^{-1}$, comparable with commercial supercapacitors operating at a similar voltage but with liquid organic electrolytes ${ }^{21,3}$. The power density of the three cell stack was maintained at almost $100 \%$ after 200 cycles and at $88 \%$ after 2000 cycles.

\section{Discussion}

Drawing on the microscopy and EIS studies, Fig. 7 shows a schematic diagram of the assumed solid-state supercapacitor structure with MWNT + ionomer hybrid electrodes, and suggests the manner in which the ionomer helps to improve dramatically the solid-state performance. The enabling roles of the ionomer in improving capacitance and rate behaviour are:

1. $\mathrm{H}^{+}$ions from the $\mathrm{H}_{2} \mathrm{SO}_{4}$ solution used in spraying were retained and mobile within the ionomer coating on the MWNTs even under dry or low humidity conditions ${ }^{40}$, while electrons readily moved along the MWNTs to the current collectors, and around the external circuit. The ionomer coverage on the MWNTs was not uniform, as shown in Fig. 3(b), and there were sufficient MWNT-MWNT junctions for electron flow through the
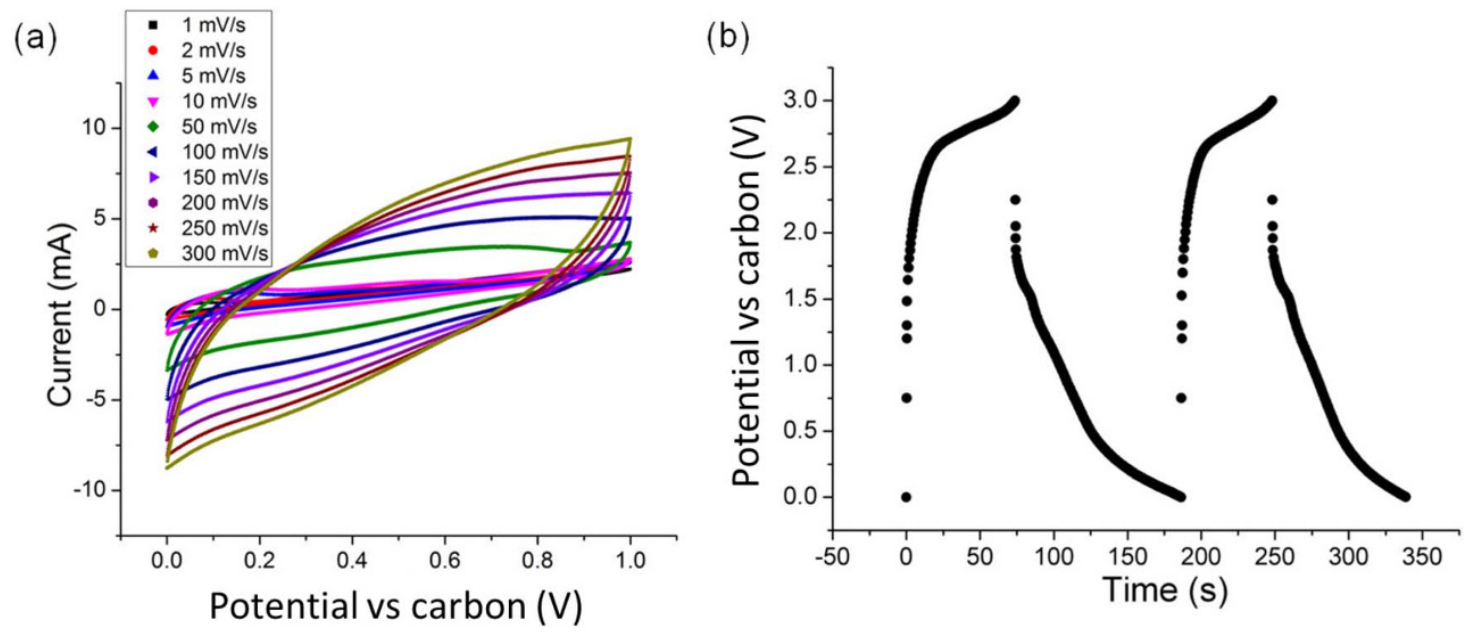

Figure 6 (a) Cyclic voltammograms of a two solid-state supercapacitors stack connected through Cu foils at a variety of scan rates; and (b) DC galvanostatic charge/discharge curves of a three solid-state supercapacitors stack charged to $3 \mathrm{~V}$ at a current density of $2 \mathrm{~A} \mathrm{~g}^{-1}$. 


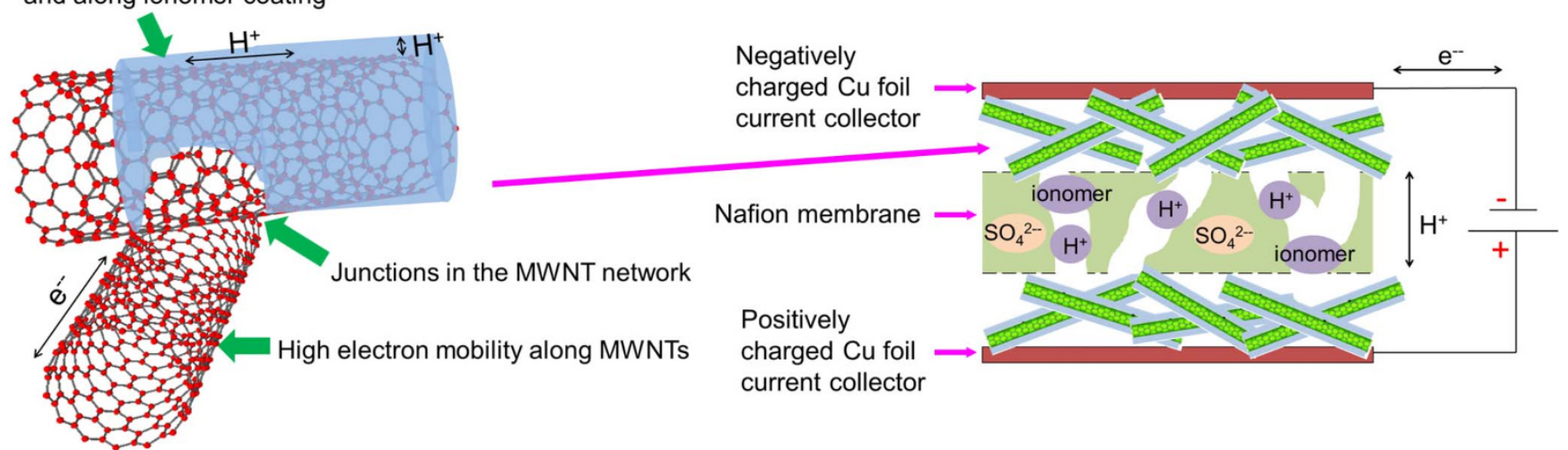

Figure $7 \mid$ A schematic diagram of a full cell solid-state supercapacitor with a detailed structure of the MWNT + ionomer hybrid electrodes.

electrode. Any residual $\mathrm{SO}_{4}{ }^{2-}$ ions were likely immobilised as the electrode was dried as part of the fabrication since neither the ionomer, the Nafion membrane or MWNTs provided a mechanism for $\mathrm{SO}_{4}{ }^{2-}$ mobility ${ }^{41}$.

2. Excellent wetting and physical contact between the coated MWNTs and the solid membrane is facilitated by the ionomer because the ionomer is chemically matched to the Nafion membrane and reduced the ion transfer resistance of $\mathrm{H}^{+33,42}$. The interaction between ionomer coated MWNTs and membrane was sufficiently strong that it could withstand moderate flexing and folding with no deterioration in performance.

In summary, all-solid-state supercapacitor cells have been fabricated by a simple one-step process in which a suspension of MWNTs and ionomer in $\mathrm{a}^{+}$containing solution was sprayed directly onto both sides of a Nafion membrane, which then acted as electrically insulating but proton conducting separator. The resulting cell including $\mathrm{Cu}$ current collectors was $230 \mu \mathrm{m}$ thick. The all-solid-state configuration offered the advantages of easy packaging, and no leakage of electrolyte even under flexing.

The specific capacitance of a fully dried solid-state supercapacitor with MWNT + ionomer hybrid electrodes was $91 \mathrm{~F} \mathrm{~g}^{-1}$ per electrode at $150 \mathrm{mV} \mathrm{s}^{-1}$, compared with $86 \mathrm{~F} \mathrm{~g}^{-1}$ for MWNTs in aqueous $1 \mathrm{M} \mathrm{H}_{2} \mathrm{SO}_{4}$. The energy density of one electrode charged to $1 \mathrm{~V}$ at $1 \mathrm{~A} \mathrm{~g}^{-1}$ was $12.9 \mathrm{Wh} \mathrm{kg}^{-1}$ and the power density was $3.3 \mathrm{~kW} \mathrm{~kg}^{-1}$, which are the highest reported in a solid-state supercapacitor configuration with EDL only capacitance. The comparatively fast kinetics and high capacitance arose because of an inter-penetrating mesoporous structure in which the MWNT scaffold offered a stable lattice for good electronic conduction and long cycling; while the ionomer coating on the MWNTs provided complementary proton conduction and promoted chemical compatibility with the membrane-type separator.

A three solid-state-cell stack was charged to $3 \mathrm{~V}$ and provided a power density of $8.9 \mathrm{~kW} \mathrm{~kg}^{-1}$ at $1 \mathrm{~A} \mathrm{~g}^{-1}$ and $9.4 \mathrm{~kW} \mathrm{~kg}^{-1}$ at $2 \mathrm{~A} \mathrm{~g}^{-1}$, comparable with commercial supercapacitors based on activated carbon and liquid inflammable organic electrolytes operating at a similar voltage. The solid-state stack was essentially chemically inert and required no special handling in a glove box or dry room, or any packaging to contain the electrolyte. The power density of this three cell stack was maintained at almost $100 \%$ after 200 cycles and at $88 \%$ after 2000 cycles.

\section{Methods}

Fabrication of membrane-based solid-state supercapacitors by a one-step spray approach. Membranes (Nafion, $70 \mu \mathrm{m}$ thickness, Du Pont) were pre-treated by immersing in $1 \mathrm{M} \mathrm{H}_{2} \mathrm{SO}_{4}$ at $60^{\circ} \mathrm{C}$ for $30 \mathrm{~min}$. Nafion ${ }^{\circledR}$, produced by Du Pont, is a functionalised polymer bearing negatively charged perfluorosulfonate $\left(-\mathrm{SO}_{2} \mathrm{~F}-\right)$ groups in the main structure, promoting proton hopping through $-\mathrm{SO}_{3}-\mathrm{H}^{+}$groups $^{41,43}$. Two MWNT-based suspensions were then sprayed onto the membranes according to the spray technique developed at Oxford University ${ }^{44-46}$ and elsewhere ${ }^{47}$ : firstly, as supplied MWNTs (Bayer MaterialScience) dispersed in $0.5 \mathrm{M} \mathrm{H}_{2} \mathrm{SO}_{4}$ aqueous solution with $0.1 \mathrm{wt} \%$ sodium dodecylbenzenesulfonate (SDBS, SigmaAldrich) surfactant; and secondly, MWNTs with 50 wt\% Nafion ionomer (SigmaAldrich) again dispersed in $0.5 \mathrm{M} \mathrm{H}_{2} \mathrm{SO}_{4}$ aqueous solution. In both cases, ultrasonication was used at $600 \mathrm{~W}$ and $20 \mathrm{kHz}$ for 15 min with a MWNT concentration of $2 \mathrm{mg} \mathrm{ml}^{-1}$ to facilitate suspension. The stable suspensions were pumped at $3 \mathrm{ml} \mathrm{min}^{-1}$ into a spray head, and atomised using compressed air at $310 \mathrm{kPa}$. The resulting atomised spray was deposited onto one side of the membrane that was maintained at $100^{\circ} \mathrm{C}$ on a heating plate connected to a vacuum chuck beneath the spray heads during spraying. The heating plate moved under the spray footprint according to a pre-programmed zig-zag pattern at a speed of $100 \mathrm{~mm} \mathrm{~s}^{-1}$, with a total spray area of $8 \mathrm{~cm} \times 8 \mathrm{~cm}$. The fugitive water in the suspension evaporated continuously during the spray process so there was no excessive build-up of liquid on the membrane and the MWNTs adhered readily, facilitating subsequent handling. The membrane with one side covered with the sprayed MWNT-based thin film electrode was then flipped and sprayed on the other side using the identical procedure. The thickness of each electrode was controlled by the spraying time to be $\sim 70 \mu \mathrm{m}$. Cu foil current collectors of $\sim 10 \mu \mathrm{m}$ in thickness were then added on the two sides by gentle manual pressing to create a symmetrical supercapacitor cell. Two, three and four identical solid-state supercapacitors were connected in series through $\mathrm{Cu}$ foils to make a stack.

Characterisation. The weight of electrodes was measured by a microbalance (Sartorius, Germany) with $0.01 \mathrm{mg}$ accuracy, and the electrode thickness was measured using a Dektak $6 \mathrm{M}$ profilometer (Veeco Instruments Inc, USA). The surface morphology of the electrodes was examined by scanning electron microscopy (JEOL $840 \mathrm{~F}$, cold field emission gun operated at $3 \mathrm{kV}$ ) and transmission electron microscopy images were obtained in a JEOL $2010\left(\mathrm{LaB}_{6}\right.$ electron gun operated at $100 \mathrm{kV})$.

Electrochemical testing of the devices was performed at room temperature using a Reference 600/EIS300 Gamry potentiostat/galvanostat and a combination of cyclic voltammetry, DC galvanostatic charge/discharge and impedance spectroscopy. Cyclic voltammetry was performed over a range of scan rates from 1 to $300 \mathrm{mV} \mathrm{s}^{-1}$, galvanostatic charge/discharge at 1-3 V with current densities of 1$2 \mathrm{~A} \mathrm{~g}^{-1}$, and electrochemical impedance spectroscopy (EIS) from 0.05 to $10^{6} \mathrm{~Hz}$ using an AC voltage of $5 \mathrm{mV}$ rms. Specific capacitance was calculated from both the $\mathrm{CVs}$ and galvanostatic charge/discharge curves. For the CVs, the specific capacitance was estimated by integrating the area under the current-potential curve and then dividing by the sweep rate, the mass of film electrode and the potential window according to ${ }^{48}$ :

$$
C=\frac{1}{m v\left(V_{a}-V_{c}\right)} \int_{V_{a}}^{V_{c}} I(V) d V
$$

where $C$ is the specific capacitance $\left(\mathrm{F} \mathrm{g}^{-1}\right), m$ is the mass of one electrode $(\mathrm{g}), v$ is the scan rate $\left(\mathrm{V} \mathrm{s}^{-1}\right), V_{a}-V_{c}$ represents the potential window $(\mathrm{V})$, and $I$ is either the charging or discharging current (A). The capacitances calculated from the CV charging and discharging current for this symmetrical carbon-based supercapacitor were similar, since no dominating reaction took place at either anodic or cathodic $\operatorname{scan}^{25,49}$.

In the galvanostatic charge/discharge process, the capacitance was estimated from the slope of the discharge curve according to Equation 6 , where the discharge current $I$ is normally used and $t$ is the corresponding discharge time (s) from a voltage $V^{25}$ : 
The maximum energy $E$ and power density $P$ can be expressed $a^{25}$ :

$$
\begin{gathered}
E=\frac{1}{2} \frac{C V^{2}}{m} \\
P=\frac{V^{2}}{4 R_{s} m}
\end{gathered}
$$

where $\mathrm{R}_{s}$ is the equivalent internal resistance ${ }^{50}$

In order to compare the performance of the solid-state supercapacitors and the equivalent electrode performance in a conventional liquid $1 \mathrm{M} \mathrm{H}_{2} \mathrm{SO}_{4}$ electrolyte, electrochemical characterisation of a single sprayed electrode was also conducted using a three-electrode configuration for the MWNT-based film on a stainless steel substrate $(2 \mathrm{~cm} \times 1 \mathrm{~cm})$ as the working electrode, and with $\mathrm{Ag} / \mathrm{AgCl}$ and $\mathrm{Pt}$ wire as the reference and counter electrodes respectively.

1. Kim, T. H. et al. Full-colour quantum dot displays fabricated by transfer printing. Nat. Photonics. 5, 176-182 (2011).

2. Bae, J. et al. Single fiber based hybridization of energy converters and storage units using graphene as electrodes. Adv. Mater. 23, 3446-3449 (2011).

3. Conway, B. E. Electrochemical Supercapacitors, Scientific Fundamentals and Technological Applications. Kluwer Academic Plenum Publishers (1999).

4. Nam, K. T. et al. Virus-enabled synthesis and assembly of nanowires for lithium ion battery electrodes. Science. 312, 885-888 (2006).

5. Naoi, K., Naoi, W., Aoyagi, S., Miyamoto, J. \& Takeo, K. New generation "nanohybrid supercapacitor" Acc. Chem. Res. 46, 1075-1083 (2013).

6. Hu, L. et al. Stretchable, porous, and conductive energy textiles. Nano. Lett. 10, 708-714 (2010).

7. Naoi, K. \& Morita, M. Advanced polymers as active materials and electrolytes for electrochemical capacitors and hybrid capacitor systmes. Electrochem. Soc. Interface. 44-48 (2008).

8. Meng, C. Z., Liu, C. H., Chen, L. Z., Hu, C. H. \& Fan, S. S. Highly flexible and allsolid-state paperlike polymer supercapacitors. Nano. Lett. 10, 4025-4031 (2010).

9. Hu, S., Rajamani, R. \& Yu, X. Flexible solid-state paper based carbon nanotube supercapacitor. Appl. Phys. Lett. 100, 104103 (2012)

10. Liu, Q., Nayfeh, O., Nayfeh, M. H. \& Yau, S. T. Flexible supercapacitor sheets based on hybrid nanocomposite materials. Nano Energy 2, 133-137 (2012).

11. Grancisco, B. E., Jones, C. M., Lee, S. \& Stoldt, C. R. Nanostructured all-solid-state supercapacitor based on Li2S-P2S5 glass-ceramic electrolyte. Appl. Phys. Lett. 100, 103902-1-4 (2012).

12. Zhou, J., Cai, J., Cai, S., Zhou, X. \& Mansour, A. N. Development of all-solid-state mediator-enhanced supercapacitors with polyvinylidene fluoride/lithium trifluoromethanesulfonate separators. J. Power Sources 196, 10479-10483 (2011)

13. Gao, H. \& Lian, K. High rate all-solid electrochemical capacitors using proton conducting polymer electrolytes. J. Power Sources 196, 8855-8857 (2011).

14. Gao, H. \& Lian, K. Characterizations of proton conducting polymer electrolytes for electrochemical capacitors. Electrochimica Acta. 56, 122-127 (2010).

15. Porada, S. et al. Water desalination using capacitive deionization with microporous carbon electrodes. Appl. Mater. Interfaces 4, 1194-1199 (2012).

16. Simon, P. \& Gogotsi, Y. Materials for electrochemical capacitors. Nat. Mater. 7, 845-854 (2008).

17. Zhang, J. et al. Dispersion of single-walled carbon nanotubes by Nafion in water/ ethanol for preparing transparent conducting films. J. Phys. Chem. C 112, 16370-16376 (2008).

18. Frackowiak, E., Jurewicz, K., Delpeux, S. \& Beguin, F. Nanotubular materials for supercapacitors. J. Power Sources 97-8, 822-825 (2001).

19. Obreja, V. V. N. On the performance of supercapacitors with electrodes based on carbon nanotubes and carbon activated material - A review. Physica E. 40, 2596-2605 (2008).

20. Signorelli, R., Ku, D. C., Kassakian, J. G. \& Schindall, J. E. Electrochemical doublelayer capacitors using carbon nanotube electrode structures. Proc. IEEE. 97, 1837-1847 (2009).

21. An, K. H. et al. Electrochemical properties of high-power supercapacitors using single-walled carbon nanotube electrodes. Adv. Funct. Mater. 11, 387-392 (2001)

22. Wang, Y. et al. Supercapacitor devices based on graphene materials. J. Phys. Chem. C 113, 13103-13107 (2009)

23. Du, C. \& Ning, P. High power density supercapacitor electrodes of carbon nanotube films by electrophoretic deposition. Nanotechnology 17, 5314-5318 (2006).

24. Hughes, M., Chen, G. Z., Shaffer, M. S. P., Fray, D. J. \& Windle, A. H. Electrochemical capacitance of a nanoporous composite of carbon nanotubes and polypyrrole. Chem. Mater. 14, 1610-1613 (2002).

25. Taberna, P. L., Simon, P. \& Fauvarque, J. F. Electrochemical characteristics and impedance spectroscopy studies of carbon-carbon supercapacitors. $J$. Electrochem. Soc. 150, 292-300 (2003).

26. Kemp, T. J. Instrumental Methods In Electrochemistry Southampton Electrochemistry Group. John Wiley \& Sons (1985).
27. Beguin, F. \& Frackowiak, E. Carbons For Electrochemical Energy Storage And Conversion Systems. CRC Press (2010).

28. Pell, W. G. \& Conway, B. E. Analysis of power limitations at porous supercapacitor electrodes under cyclic voltammetry modulation and dc charge. J. Power Sources 96, 57-67 (2001).

29. Kerres, J. A. Development of ionomer membranes for fuel cells. J. Membrane. Sci. 185, 3-27 (2001).

30. Niu, C., Sichel, E. K., Hoch, R., Moy, D. \& Tennent, H. High power electrochemical capacitors based on carbon nanotube electrodes. Appl. Phys. Lett. 70, 1480-1482 (1997).

31. Portet, C., Yushin, G. \& Gogotsi, Y. Electrochemical performance of carbon onions, nanodiamonds, carbon black and multiwalled nanotubes in electrical double layer capacitors. Carbon. 45, 2511-2518 (2007).

32. Beguin, F. \& Frackowiak, E. Supercapacitors, Materials, Systems and Applications. Wiley-VCH (2013).

33. Choi, B. G., Hong, J., Hong, W. H., Hammond, P. T. \& Park, H. S. Facilitated ion transport in all-solid-state flexible supercapacitors. ACS Nano. 5, 7205-7213 (2011).

34. Cole, K. S. \& Cole, R. H. Dispersion and absorption in dielectrics I. alternating current characteristics. J. Chem. Phys. 9, 341-351 (1941)

35. Futaba, D. N. et al. Shape-engineerable and highly densely packed single-walled carbon nanotubes and their application as super-capacitor electrodes. Nat. Mater. 5, 987-994 (2006).

36. Liu, Q., Nayfeh, M. H. \& Yau, S. T. Brushed-on flexible supercapacitor sheets using a nanocomposite of polyaniline and carbon nanotubes. J. Power Sources 195, 7480-7483 (2010)

37. Zhou, X., Peng, C. \& Chen, G. Z. 20 V stack of aqueous supercapacitors with carbon (-), titanium bipolar plates and CNT-polypyrrole composite (+). AIChE J. 58, 974-983 (2012).

38. Wei, D. \& Ng, T. W. Application of novel room temperature ionic liquids in flexible supercapacitors. Electrochem. Commun. 11, 1996-1999 (2009).

39. Zhang, S., Peng, C., Ng, K. C. \& Chen, G. Z. Nanocomposites of manganese oxides and carbon nanotubes for aqueous supercapacitor stacks. Electrochimica Acta 55, $7447-7453(2010)$

40. Ahn, S. Y., Lee, Y. C., Ha, H. Y., Hong, S. A. \& On, I. H. Effect of the ionomers in the electrode on the performance of PEMFC under non-humidifying conditions. Electrochimica Acta. 50, 673-676 (2004).

41. Doyle, M., Lewittes, M. E., Roelofs, M. G., Perusich, S. A. \& Lowrey, R. E. Relationship between ionic conductivity of perfluorinated ionomeric membranes and nonaqueous solvent properties. J. Membrane. Sci. 184, 257-273 (2001).

42. Lufrano, F. \& Staiti, P. Conductivity and capacitance properties of a supercapacitor based on Nafion electrolyte in a nonaqueous system. Electrochem. Solid. St. 7, 447-450 (2004).

43. Kreuer, K. D. Proton conductivity: materials and applications. Chem. Mater. 8, 610-641 (1996).

44. Zhao, X. et al. Spray deposition of steam treated and functionalized single-walled and multi-walled carbon nanotube films for supercapacitors. Nanotechnology $\mathbf{2 0}$, 065605 (2009).

45. Mendoza-Sanchez, B., Rasche, B., Nicolosi, V. \& Grant, P. S. Scaleable ultra-thin and high power density graphene electrochemical capacitor electrodes manufactured by aqueous exfoliation and spray deposition. Carbon 52, 337-346 (2012).

46. Huang, C. et al. Layer-by-layer spray deposition and unzipping of single-wall carbon nanotube-based thin film electrodes for electrochemical capacitors. Carbon 61, 525-536 (2013)

47. Singh, N. et al. Paintable Battery. Sci. Rep. 2, 481; doi:10.1038/srep00481(2012).

48. Srinivasan, V. \& Weidner, J. W. Capacitance studies of cobalt oxide films formed via electrochemical precipitation. J. Power Sources 108, 15-20 (2002).

49. Jones, T. W., Lewandowski, A. P. \& Donne, S. W. Discharge performance of a primary alkaline $\mathrm{CuO}$ cathode material prepared via a novel non-aqueous precipitation method. Electrochimica Acta 56, 4996-5002 (2011).

50. Stoller, M. D. \& Ruoff, R. S. Best practice methods for determining an electrode material's performance for ultracapacitors. Energy Environ Sci. 3, 1294-1301 (2010)

\section{Acknowledgments}

The authors would like to thank Prof John Sykes, Dr Colin Johnston and Dr Chaopeng Fu for their advice. This work was supported by the Korea Institute of Energy Technology Evaluation and Planning (KETEP) (20128510010080).

\section{Author contributions}

C.H. performed the experiments, analysed data and co-wrote the manuscript. P.S.G. directed the study, read and guided the data analysis, co-wrote and edited the paper.

\section{Additional information}

Supplementary information accompanies this paper at http://www.nature.com/ scientificreports

Competing financial interests: The authors declare no competing financial interests. 
How to cite this article: Huang, C. \& Grant, P.S. One-step spray processing of high power all-solid-state supercapacitors. Sci. Rep. 3, 2393; DOI:10.1038/srep02393 (2013). cc) (1) \&) $\odot$ This work is licensed under a Creative Commons AttributionBy no NonCommercial-NoDerivs 3.0 Unported license. To view a copy of this license, visit http://creativecommons.org/licenses/by-nc-nd/3.0 